\title{
Effects of hypoxia on predator-prey interactions between juvenile Carcinus aestuarii and Musculista senhousia
}

\author{
Michele Mistri* \\ Department of Biology, University of Ferrara, Via L. Borsari 46, 44100 Ferrara, Italy
}

\begin{abstract}
The impact of hypoxia upon predator-prey interactions between juvenile Mediterranean shore crabs Carcinus aestuarii and the mytilid Musculista senhousia was investigated in laboratory and mesocosm experiments. These species are among the most abundant macrobenthic organisms in the Sacca di Goro, a lagoon in the Po River deltaic system (Adriatic Sea, Italy). The effect of normoxia and hypoxia on juvenile $C$. aestuarii predatory behaviour was examined in laboratory experiments; factors were prey size (small, medium and large) and oxygen level (normoxic: $>6.0 \mathrm{mg}$ $\mathrm{O}_{2} \mathrm{l}^{-1}$; moderately hypoxic: 3.0 to $1.5 \mathrm{mg} \mathrm{O}_{2} \mathrm{l}^{-1}$; severely hypoxic: $<1.5 \mathrm{mg} \mathrm{O}_{2} \mathrm{l}^{-1}$ ). The prey-handling time of crabs was largely increased by hypoxia. In mesocosm experiments, 2 densities of M. senhousia (40 and 200 mussels tank ${ }^{-1}$ ) were exposed to juvenile $C$. aestuarii $\left(1 \mathrm{crab} \mathrm{tank}^{-1}\right.$ ) at 2 oxygen levels (normoxic: $>6.0 \mathrm{mg} \mathrm{O}_{2} \mathrm{l}^{-1}$; severely hypoxic: $<1.5 \mathrm{mg} \mathrm{O}_{2} \mathrm{l}^{-1}$ ). Consumption rates of $C$. aestuarii were lower under hypoxia, resulting in reduced mortality rates of mussels. Predation was inversely dependent. Short-term hypoxia, therefore, reduced the ability of crabs to forage on mussels efficiently and increased mussel survival, probably reducing the transfer of bivalve prey to predatory crabs.
\end{abstract}

KEY WORDS: Hypoxia · Predator-prey · Carcinus aestuarii · Musculista senhousia · Sacca di Goro

\section{INTRODUCTION}

Oxygen deficiency events affect coastal and estuarine communities almost worldwide (Diaz \& Rosenberg 1995, Gray et al. 2002). The ecological impact of such events ranges from extensive mortality of benthic organisms to the alteration of biological interactions among them (Jørgensen 1980, Justic et al. 1987, Nilsson \& Rosenberg 1994, Diaz \& Rosenberg 1995, Ritter \& Montagna 1999). Fishes are more sensitive to reduced oxygen concentrations than crustaceans, followed by annelids, and bivalves are the most tolerant (Rosenberg et al. 1991, Nilsson \& Rosenberg 1994). As an example, in tolerance experiments conducted at $10^{\circ} \mathrm{C}$ and $0.2 \mathrm{mg} \mathrm{O}_{2} \mathrm{l}^{-1}$, Mytilus edulis survived for more than $1000 \mathrm{~h}$, whereas Nereis diversicolor survived for ca. 200 h, and Carcinus maenas for less than
$100 \mathrm{~h}$ (Dries \& Theede 1974, in Gray et al. 2002). In response to low-oxygen events, behavioural avoidance of unfavourable conditions may result in the migration of mobile organisms (Pihl et al. 1991, Das \& Stickle 1994), while sessile and infaunal species, unable to avoid or escape oxygen-depleted waters, initiate a series of responses to hypoxia according to its severity (Diaz \& Rosenberg 1995, Gray et al. 2002). A consequence of these behavioural changes is that predator-prey dynamics can also be altered (Taylor \& Eggleston 2000, Brante \& Hughes 2001, Tallqvist 2001, Seitz et al. 2003).

In the Sacca di Goro, a large, microtidal lagoon in the northern Adriatic Sea $\left(44^{\circ} 45^{\prime} \mathrm{N}, 12^{\circ} 15^{\prime} \mathrm{E}\right.$; NE Italy), small-scale, hypoxic events are common, particularly in summer (Colombo et al. 1994). Bottom water can change quickly from normoxic to hypoxic conditions, 
or vice versa, and these changes can be sustained episodically (hours) or chronically (days) (Mistri 2002). The Sacca is a lagoon in which physical disturbance has an overriding influence in structuring benthic communities. As a consequence, animal assemblages are characterised by a small number of species, a strong dominance in abundance by a few of these species, and relatively low diversity (Mistri et al. 2001a,b).

In the Sacca, a key predator-prey system is constituted by the Mediterranean shore crab Carcinus aestuarii and the epibenthic mytilid Musculista senhousia; these 2 species are among the most abundant macrobenthic organisms in the lagoon (Mistri et al. 2001b). The non-native $M$. senhousia was accidentally introduced in the 1990s (Mistri et al. 2004). This thinshelled species fits the classical concept of an opportunist, being short-lived (max. 2 yr), of small body size (max. $35 \mathrm{~mm}$ shell length), fast-growing (up to $25 \mathrm{~mm}$ in the first year), and experiencing dramatic population fluctuations (Crooks 1996, Mistri 2002). The mussel typically lives on the surface of shallow, subtidal, soft sediments and uses byssal threads to create byssal bags. When occurring in high densities, a mat is formed on the sediment surface. In the Sacca, M. senhousia shows very variable abundance, depending on the extension and thickness of the mats, and typically ranges from tens to a few thousand individuals (ind.) $\mathrm{m}^{-2}$ (Mistri 2002, Mistri et al. 2004). The native shore crab C. aestuarii is a large (up to $70 \mathrm{~mm}$ carapace width) epibenthic predator that has a fairly broad diet, comprising many taxa, particularly bivalve molluscs, polychaetes and small crustaceans. The shore crab can live at a wide range of salinities ( 8 to $35 \mathrm{psu}$ ) and temperatures $\left(5\right.$ to $30^{\circ} \mathrm{C}$ ) (Mori et al. 1990 , author's pers. obs.), and shows very variable abundance, typically ranging between 0.5 and 40 ind. $\mathrm{m}^{-2}$ (Mistri et al. 2001a). Adult crabs (>50 mm carapace width) are voracious predators of $M$. senhousia, and are able to break all sizes of mussel within a few seconds (Mistri 2003).

The present study examined juvenile crabs. Although in the Sacca, especially in summer, hypoxia is a common event (Colombo et al. 1994), no information exists on its effects on benthic predator-prey dynamics. By increasing the susceptibility of prey to predators, hypoxia may change the structure of benthic communities (Jørgensen 1980, Pihl et al. 1992). The aim of this study was to examine the effects of hypoxia on predator-prey interactions between juvenile Carcinus aestuarii and Musculista senhousia through a series of laboratory experiments. The behavioural response of C. aestuarii to hypoxia was examined by quantifying and comparing the handling time of crabs presented with $M$. senhousia of different sizes under conditions of normoxia, moderate hypoxia and severe hypoxia. Additionally, in further predator-prey mesocosm experiments, the foraging behaviour of the crab was examined to ascertain whether or not hypoxia alters predator-prey dynamics.

\section{MATERIALS AND METHODS}

Effect of hypoxia on predatory behaviour. Species of the Asian date mussel Musculista senhousia were collected with a hand rake in the Sacca di Goro (Po River Delta, Adriatic Sea) in June 2003, and maintained in suspended cages in an outdoor $5000 \mathrm{ltank}$, in flowing seawater (salinity $27 \pm 1 \mathrm{psu}$, temperature $26 \pm$ $2{ }^{\circ} \mathrm{C}$ ) with natural phytoplankton. I used 50 randomly selected mussels to calculate the relationship between flesh ash-free dry weight, AFDW (mussels dried at $80^{\circ} \mathrm{C}$ for $48 \mathrm{~h}$ and combusted at $450^{\circ} \mathrm{C}$ for $4 \mathrm{~h}$ ) and shell length (SL). The relationship had the form AFDW = 0.0039 SL $^{2.609}\left(\mathrm{r}^{2}=0.88 ; \mathrm{p}<0.05\right)$, and was used to predict the weight of each prey presented to a crab in subsequent trials. Juvenile Mediterranean shore crabs Carcinus aestuarii of 30.1 to $34.0 \mathrm{~mm}$ carapace width were collected in the Sacca during the same period using dip nets. Crabs were held in flowing seawater in an indoor 500 l, aerated, holding tank, and fed ad libitum with mussel flesh. Sediment, faecal material, and debris were removed from the tank daily. Only intact and actively feeding crabs were utilised for predation trials, and their hunger levels were standardised by a $48 \mathrm{~h}$ long starvation.

The effect of normoxia and hypoxia on Carcinus aestuarii predatory behaviour was tested through the manipulation of oxygen levels in the water in 4 small (20 1), indoor, Plexiglas aquaria half-filled with seawater. Low oxygen levels were maintained by bubbling air and nitrogen at $97 \%$ purity with 2 air stones; normoxic conditions were maintained by bubbling only air. In the severely hypoxic treatment, a sheet of bubble-wrap plastic was placed on the water surface of each aquarium to limit gas exchange. In the experimental design, factors were (1) prey size (small: $<15.0 \mathrm{~mm}$ SL; medium: 15.1 to $20.0 \mathrm{~mm}$ SL; large: $>20.1 \mathrm{~mm} \mathrm{SL}$ ) and (2) oxygen level (normoxic: > $6.0 \mathrm{mg}$ $\mathrm{O}_{2} \mathrm{l}^{-1}$ [range: 6.0 to $8.3 \mathrm{mg} \mathrm{O}_{2} \mathrm{l}^{-1}$ ]; moderately hypoxic: 3.0 to $1.5 \mathrm{mg} \mathrm{O}_{2} \mathrm{l}^{-1}$; severely hypoxic: $<1.5 \mathrm{mg} \mathrm{O}_{2} \mathrm{l}^{-1}$ ). Mussels were offered individually, since clumping did not seem to provide refuge to the species from crab predation (Mistri 2004). Each combination of prey size and oxygen treatment was replicated 4 times. Oxygen concentration was continuously monitored by an OxyGuard ${ }^{\circledR}$ Mk III oxygen probe. A crab was placed into each aquarium, and nitrogen bubbling was begun; the moderately hypoxic condition was reached within $1 \mathrm{~h}$, the severely hypoxic condition within $2 \mathrm{~h}$. The prey was then introduced into the aquarium. In each feed- 
ing trial, breaking and eating times (Elner \& Hughes 1978) were carefully recorded with a stopwatch. The sum of breaking and eating times constituted the prey handling time, which was then used to calculate preyprofitability (Elner \& Hughes 1978) by dividing the estimated flesh weight of the prey by handling time.

A 2-way ANOVA, with oxygen level (N: normoxic; $\mathrm{MH}$ : moderately hypoxic; $\mathrm{SH}$ : severely hypoxic), and prey size (S: small; M: medium; L: large) as fixed factors was used. Before analysis, data were checked for homogeneity of variance (Levene's test), and logarithmic (for behavioural data) and square-root (for profitability data) transformations were used (Underwood 1997). Post hoc pairwise comparisons were made using Tukey's HSD test (Sokal \& Rohlf 1981). The components of handling time (breaking and eating time) at each prey size were also analysed by 2-way ANOVA after log-transformation, with oxygen level and prey size as factors.

Effect of hypoxia on predator-prey dynamics. To evaluate crab responses to prey density and oxygen level, 2 densities of medium-sized (15.1 to $20.0 \mathrm{~mm} \mathrm{SL}$ ) Musculista senhousia (40 and 200 mussels per tank, corresponding to 66 and 328 mussels $\mathrm{m}^{-2}$ ) were exposed to juvenile Carcinus aestuarii (1 crab per tank, corresponding to $2 \mathrm{crabs} \mathrm{m}^{-2}$ ) at 2 oxygen levels (normoxic and severely hypoxic). The experimental densities of mussels used in this study represent a low-tomoderate range of natural densities of $M$. senhousia in the Sacca di Goro (Mistri 2002). Episodic hypoxic events in the Sacca (hypoxia may range from a few hours to days: Colombo et al. 1994, Mistri 2002) helped determine a realistic duration for the experiments. I filled 8 outdoor mesocosm tanks $(78 \times 78 \times 15 \mathrm{~cm})$ with unfiltered seawater. Mussels were introduced into each tank, being at least $10 \mathrm{~cm}$ from the sides to avoid edge effects on predation rates (Eggleston et al. 1992). A sheet of bubble-wrap plastic was placed on the water surface of 4 tanks randomly assigned to the severely hypoxic treatment, $\mathrm{SH}\left(<1.5 \mathrm{mg} \mathrm{O}_{2} \mathrm{l}^{-1}\right)$, to limit gas exchange. These $4 \mathrm{SH}$ tanks were then bubbled with nitrogen at $97 \%$ purity, monitored by the OxyGuard $^{\circledR}$ Mk III oxygen probe. The hypoxic condition was reached within $5 \mathrm{~h}$ of beginning nitrogen bubbling. The remaining 4 tanks were assigned to the normoxic treatment, $\mathrm{N}\left(6.0 \mathrm{mg} \mathrm{O} \mathrm{O}_{2} \mathrm{l}^{-1}\right)$, and the oxygen level was maintained by bubbling air with 2 Sonic $^{\circledR}$ Premier 3900 air pumps in each tank. C. aestuarii were starved for $48 \mathrm{~h}$ prior to being released in the centre of each tank. I conducted two $24 \mathrm{~h}$ feeding trials at each mussel density. Prey mortality was quantified by counting surviving mussels.

Consumption (no. of mussels eaten $24 \mathrm{~h}^{-1}$ ) and mortality rates (no. of mussels eaten $24 \mathrm{~h}^{-1}$ as a function of mussel density) of Musculista senhousia were analysed by a 2-way, fixed-factor ANOVA using mussel density (LD: low density, 40 ind tank $^{-1}$; MD: medium density, 200 ind $\operatorname{tank}^{-1}$ ) and oxygen level (N: normoxia; SH: hypoxia) as factors. Before analysis, data were checked for homogeneity of variance (Levene's test), and logarithmic (for consumption data) and arcsine (for mortality data) transformations were used (Underwood 1997). Post hoc pairwise comparisons were made using Tukey's HSD test (Sokal \& Rohlf 1981).

\section{RESULTS}

\section{Effect of hypoxia on crab and mussel behaviour}

Under severe hypoxia, Carcinus aestuarii often raised its cephalotorax towards the water surface by stretching its walking legs. This behaviour enables crabs to oxygenate in suitably shallow water (Taylor et al. 1977). Moreover, crabs often paused for long periods while handling prey under severe hypoxia. Under hypoxia Musculista senhousia closed its valves, which interrupted pumping activity.

The analysis of handling time (Fig. 1) revealed that both factors, oxygen level and prey size, were statistically significant, but their interaction was not (Table 1). Crabs took longer to handle medium and large mussels than small mussels (Tukey HSD test: S vs M, p < 0.05; $\mathrm{S}$ vs L, $\mathrm{p}<0.001$; $\mathrm{M}$ vs L, $\mathrm{p}=0.09$ ). Moreover, handling time was shorter under normoxia than under moderate and severe hypoxia ( $\mathrm{N}$ vs $\mathrm{MH}, \mathrm{p}<0.001 ; \mathrm{N}$ vs $\mathrm{SH}, \mathrm{p}<$ $0.0005 ; \mathrm{MH}$ vs $\mathrm{SH}, \mathrm{p}<0.001)$. The components of handling time, breaking time (Bt) and eating time (Et) also varied significantly (Fig. 1, Table 2). Breaking time varied as a function of oxygen level ( $\mathrm{N}$ vs $\mathrm{MH}, \mathrm{p}=0.07$; $\mathrm{N}$ vs $\mathrm{SH}, \mathrm{p}<0.001 ; \mathrm{MH}$ vs $\mathrm{SH}, \mathrm{p}<0.001)$ but not of prey size. Eating time varied as a function of prey size (S vs $\mathrm{M}, \mathrm{p}=0.23$; $\mathrm{S}$ vs L, $\mathrm{p}<0.0005 ; \mathrm{M}$ vs L, $\mathrm{p}<0.05$ ), and of oxygen level ( $\mathrm{N}$ vs $\mathrm{MH}, \mathrm{p}<0.05$; $\mathrm{N}$ vs $\mathrm{SH}, \mathrm{p}<$ $0.0005 ; \mathrm{MH}$ vs $\mathrm{SH}, \mathrm{p}=0.08)$, but their interaction was not significant.

Under normoxic conditions, prey-profitability ranged from about $0.03 \mathrm{mg} \mathrm{s}^{-1}$ for small and medium mussels to $0.05 \mathrm{mg} \mathrm{s}^{-1}$ for large mussels. Under mod-

Table 1. Carcinus aestuarii preying on Musculista senhousia. Results of 2-way ANOVA of handling time with fixed factors prey size (Lprey) and oxygen level (Oxy)

\begin{tabular}{|lrrrr|}
\hline Factor & df & MS & $F$ & $p$ \\
\hline Lprey (L) & 2 & 1.402 & 11.502 & 0.0002 \\
Oxy (O) & 2 & 6.470 & 53.091 & 0.0001 \\
L $\times$ O & 4 & 0.135 & 1.105 & 0.374 \\
Error & 27 & 0.122 & & \\
\hline
\end{tabular}



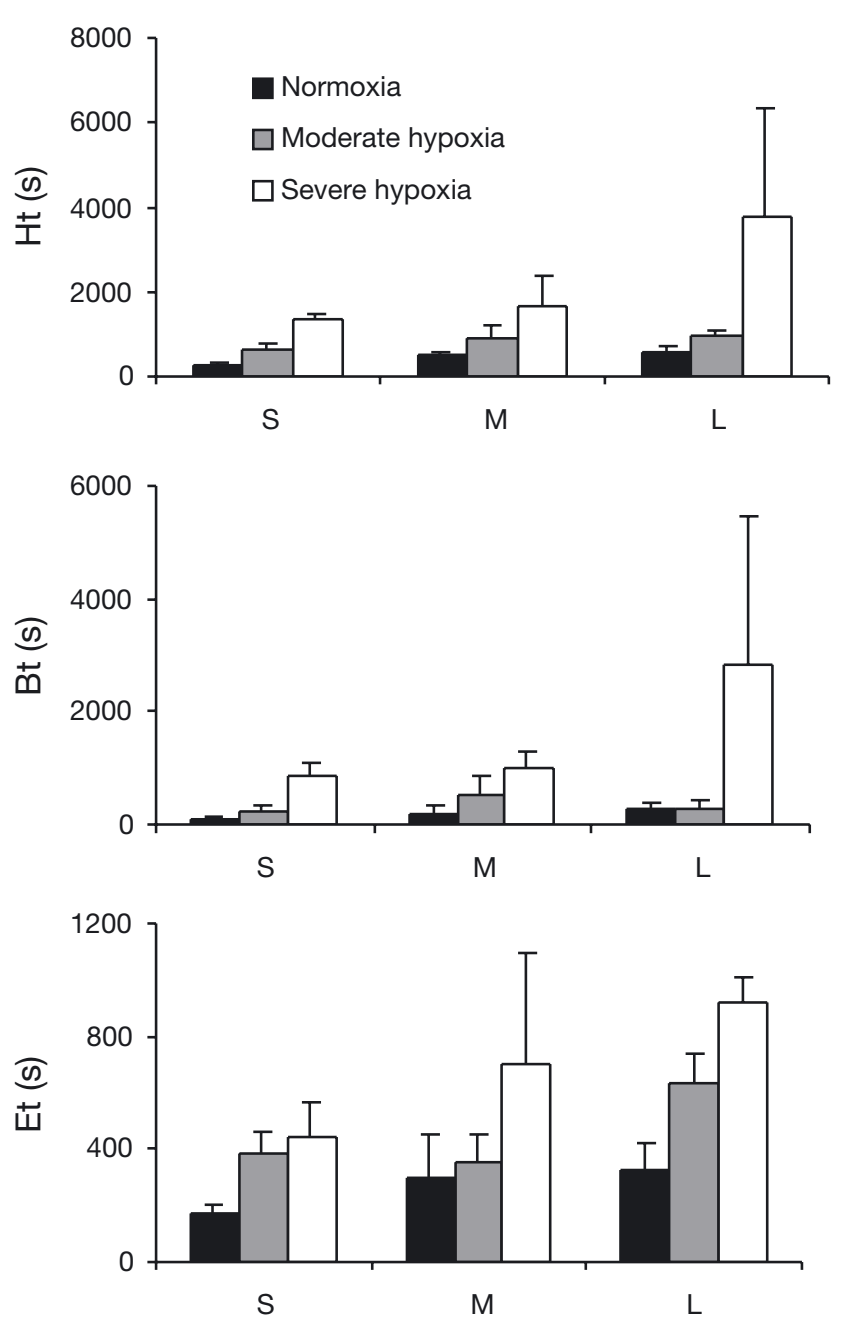

Fig. 1. Carcinus aestuarii preying on Musculista senhousia. Duration of prey handling time $(\mathrm{Ht})$, breaking time $(\mathrm{Bt})$, and eating time (Et) under conditions of normoxia, moderate hypoxia, and severe hypoxia. Data are means (+SD) of 4 trials. S: small prey; M: medium prey; L: large prey

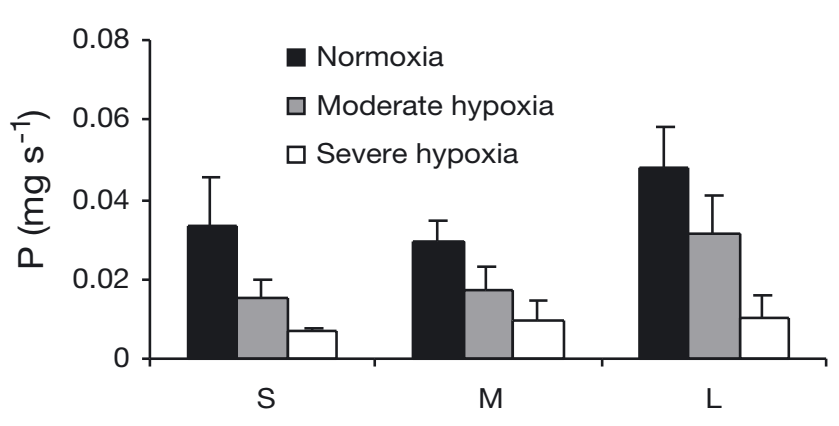

Fig. 2. Carcinus aestuarii preying on Musculista senhousia. Prey-profitability (P) on small (S) medium (M) and large (L) prey erate hypoxia, prey-profitability values ranged from about $0.02 \mathrm{mg} \mathrm{s}^{-1}$ for small and medium prey to $0.03 \mathrm{mg} \mathrm{s}^{-1}$ for large prey, while under severe hypoxia, the values were 0.007 for small, 0.009 for medium and $0.01 \mathrm{mg} \mathrm{s}^{-1}$ for large mussels (Fig. 2). Oxygen level and prey size were significant, but their interaction was not (Table 3). Prey-profitability was significantly higher for large mussels than for small or medium mussels (Tukey HSD test: $\mathrm{S}$ vs $\mathrm{M}, \mathrm{p}=0.89$; $\mathrm{S}$ vs $\mathrm{L}, \mathrm{p}<0.005 ; \mathrm{M}$ vs $\mathrm{L}, \mathrm{p}<0.01$ ), and decreased greatly from normoxic to moderately and severely hypoxic conditions ( $\mathrm{N}$ vs $\mathrm{MH}, \mathrm{N}$ vs $\mathrm{SH}, \mathrm{MH}$ vs $\mathrm{SH}$ : all $\mathrm{p}<0.0005)$.

\section{Effect of hypoxia on predator-prey dynamics}

Consumption rates of individual Carcinus aestuarii differed significantly according to oxygen level and mussel density (Fig. 3a); the interaction effect was not significant (Table 4). Crabs ate more mussels under normoxia than hypoxia (Tukey HSD test: $\mathrm{N}$ vs $\mathrm{SH}, \mathrm{p}<$ 0.001). In addition, significantly more Musculista senhousia were consumed at the moderate (200 mussels per tank) density than at the low (40 mussels per tank) density (LD vs MD: $\mathrm{p}<0.001$ ).

(a) Consumption rates

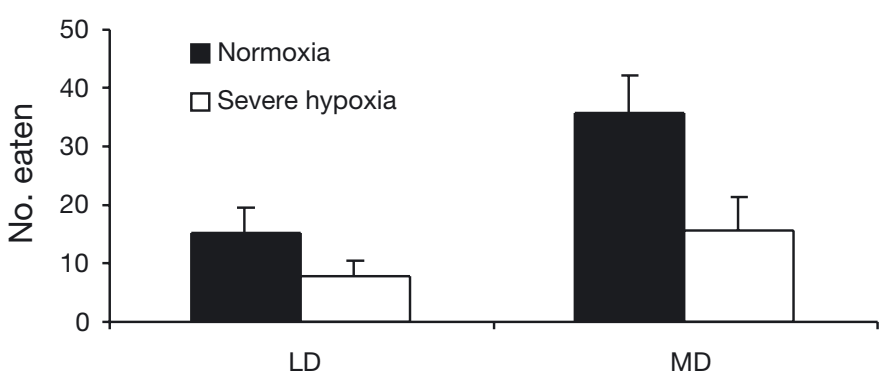

(b) Mortality rates

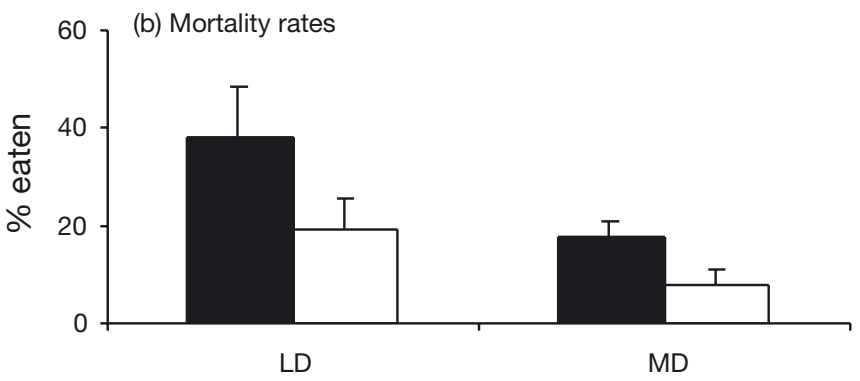

Fig. 3. Carcinus aestuarii preying on Musculista senhousia. (a) Consumption rates (no. of mussels eaten $24 \mathrm{~h}^{-1}$ ) and (b) mortality rates (no. of mussels eaten $24 \mathrm{~h}^{-1}$ as a function of mussel density under conditions of normoxia and severe hypoxia. LD, MD: light (40 mussels per tank) and medium (200 mussels per tank) densities respectively. Data are means (+SD) of 4 trials 
Mortality rates of Musculista senhousia also differed significantly as a function of oxygen level and mussel density (Fig. 3b), while the interaction effect was not significant (Table 5). Mortality rates were higher under normoxia ( $\mathrm{N}$ vs $\mathrm{SH}, \mathrm{p}<0.001)$ and at low mussel density (LD vs MD: $\mathrm{p}<0.001$ ).

Table 2. Carcinus aestuarii preying on Musculista senhousia. Results of 2-way ANOVA of breaking time (Bt) and eating time (Et) with fixed factors prey size (Lprey) and oxygen level (Oxy)

\begin{tabular}{|lrrrl|}
\hline Factor & df & \multicolumn{1}{c}{ MS } & \multicolumn{1}{c|}{$F$} & $\mathrm{p}$ \\
\hline Bt & & & & \\
Lprey (L) & 2 & 1.270 & 3.049 & 0.064 \\
Oxy (O) & 2 & 12.175 & 29.215 & 0.0001 \\
L $\times$ O & 4 & 0.448 & 1.075 & 0.388 \\
Error & 27 & 0.417 & & \\
Et & & & & \\
Lprey & 2 & 1.207 & 9.459 & 0.0008 \\
Oxy & 2 & 2.513 & 19.683 & 0.0001 \\
L $\times$ O & 4 & 0.114 & 0.896 & 0.480 \\
Error & 27 & 0.128 & & \\
\hline
\end{tabular}

Table 3. Carcinus aestuarii preying on Musculista senhousia. Results of 2-way ANOVA of prey-profitability with fixed factors prey size (Lprey) and oxygen level (Oxy)

\begin{tabular}{|lrrrr|}
\hline Factor & df & MS & \multicolumn{1}{c|}{$F$} & \multicolumn{1}{c|}{ p } \\
\hline Lprey (L) & 2 & 0.0045 & 8.179 & 0.0017 \\
Oxy (O) & 2 & 0.0285 & 52.071 & 0.0001 \\
L $\times$ O & 4 & 0.0008 & 1.499 & 0.230 \\
Error & 27 & 0.0005 & & \\
\hline
\end{tabular}

Table 4. Carcinus aestuarii preying on Musculista senhousia. Results of 2-way ANOVA of consumption rates with fixed factors oxygen level (Oxy) and prey density (DP)

\begin{tabular}{|lrccl|}
\hline Factor & df & MS & $F$ & \multicolumn{1}{c|}{$p$} \\
\hline Oxy $(\mathrm{O})$ & 1 & 0.454 & 25.461 & 0.00029 \\
DP & 1 & 0.461 & 25.848 & 0.00027 \\
O $\times$ DP & 1 & 0.006 & 0.336 & 0.573 \\
Error & 12 & 0.018 & & \\
\hline
\end{tabular}

Table 5. Carcinus aestuarii preying on Musculista senhousia. Results of 2-way ANOVA of mortality rates with fixed factors oxygen level (Oxy) and prey density (DP)

\begin{tabular}{|lrrrl|}
\hline Factor & df & MS & $F$ & \multicolumn{1}{c|}{$p$} \\
\hline Oxy & 1 & 0.089 & 19.494 & 0.00084 \\
DP & 1 & 0.109 & 23.753 & 0.00038 \\
O $\times$ DP & 1 & 0.009 & 2.048 & 0.178 \\
Error & 12 & 0.005 & & \\
\hline
\end{tabular}

\section{DISCUSSION}

Hypoxia significantly affected predator-prey interactions between juvenile Carcinus aestuarii and Musculista senhousia. In laboratory experiments, hypoxia (both moderate and severe) reduced prey-handling efficiency of $C$. aestuarii, as observed in C. maenas feeding on Mytilus edulis under hypoxia (ca. $1 \mathrm{mg} \mathrm{\textrm {O } _ { 2 }}$ $\mathrm{l}^{-1}$ : Brante \& Hughes 2001). In the present study, of the 2 components of prey-handling time, breaking time responded to severe hypoxia, increasing nearly 3 -fold, while eating time also responded to moderate and severe hypoxia; time spent ingesting and digesting mussels therefore also accounted for a proportion of prey-handling effort. Crabs compensate for short-term hypoxia by increasing ventilation, and this requires energy that is drawn from the energy available for locomotion and feeding (Taylor et al. 1977). Therefore, under severe hypoxia, crabs are less active because they are energy-limited (Das \& Stickle 1994). Through this energetic limitation, and by significantly increasing its prey-handling time, hypoxic events in the natural environment may place juvenile $C$. aestuarii at greater risk to competition and predation, due to the increase in the time of exposure during foraging (in the Sacca, competitors and predators are mostly larger conspecific crabs or shorebirds such as Larus argentatus and Ardea cinerea; G. Pagnoni pers. comm., author's pers. obs.).

In the outdoor mesocosm experiments, when Carcinus aestuarii foraged upon Musculista senhousia under normoxia, mussels suffered a higher risk of mortality at low than at medium density, which is indicative of a Type II functional response. This pattern of inversely density-dependent mortality of mussel prey under normoxia is consistent with previous findings regarding predatory dynamics of adult ( $>50 \mathrm{~mm}$ carapace wt) crabs (Mistri 2003), and is characteristic of predator-prey interactions between crabs and many bivalve species (Seitz et al. 2001). Under hypoxia, the proportional mortality of mussels was also inversely density-dependent but lower, indicating that mussels attained a partial refuge from crab predation. Seitz et al. (2001) suggested 2 strategies of antipredator defence in bivalve prey (i.e. armour or avoidance): thin-shelled prey avoid predators by reducing encounter rates through deep burial, and/or living at low density; thick or ornamented-shelled prey, which are epibenthic or shallow-burrowers, reduce predation by reducing the handling efficiency of predators. M. senhousia is a thin-shelled (i.e. not armoured), epibenthic (i.e. not avoidant) species and no size refuge (Mistri 2003). Under normal conditions, it must rely on aggregative behaviour as a refuge from predation by shore crabs. In the mesocosm experiments, hypoxia 
promoted a partial refuge for mussels by reducing the handling efficiency of crabs. Thus, hypoxia apparently reduced the transfer of benthic production from mussels to epibenthic predators such as $C$. aestuarii. In the Sacca di Goro, this potential loss of trophic transfer from mussel to crabs under hypoxia is likely to be significant, since $C$. aestuarii shows a marked preference for $M$. senhousia compared to other bivalve prey (Mistri 2004).

The reduced predation impact of Carcinus aestuarii on Musculista senhousia under hypoxia agrees with the consumer stress model (Menge \& Sutherland 1987) observed in recent studies on predator-prey interactions under hypoxia (Taylor \& Eggleston 2000, Seitz et al. 2003). Hypoxia affected the predator-prey interaction between the blue crab Callinectes sapidus and the infaunal, soft-shelled clam Mya arenaria by hindering crab foraging despite the clams' migration towards the sediment surface (Taylor \& Eggleston 2000). Similarly, the Baltic clam Macoma balthica showed a reduced mortality under hypoxia rather than normoxia, indicating that blue crabs were more adversely affected by hypoxia than the clams (Seitz et al. 2003). If, in areas subjected to hypoxia, such a disturbance is more stressful to the predator than to its prey, these areas may serve as a refuge from predation. Such a refuge, however, may depend on the duration of the hypoxic disturbance event, since prolonged hypoxia can cause mass mortality of benthic fauna (Stachowitsch 1984, Ueda et al. 2000). For instance, an unusual, prolonged (more than 1 wk) hypoxic event during summer 1999 in the Sacca di Goro triggered mass mortality of $M$. senhousia (over $90 \%$ of the mussel population: Mistri 2002).

Benthic organisms respond to declining oxygen concentrations in several ways, depending on their taxonomic and ecological position (Rosenberg et al. 1991). Sessile and infaunal species may increase their ventilation rates (DeFur et al. 1990), extend siphons upwards into the water column, or migrate vertically towards the sediment surface (Diaz \& Rosenberg 1995); and they may reduce their activity and shift towards anaerobic metabolism (Kluytmans et al. 1983, Hochachka 1997, Greenway \& Storey 1999). In contrast, more mobile organisms, such as crustaceans and fishes, migrate away from oxygen-depleted waters (Pihl et al. 1991, Das \& Stickle 1994, Lenihan et al. 2001). Predators may also follow the spatially dynamic transition zone between normoxic and hypoxic zones, and exploit prey that have been stressed by hypoxic events (Pihl et al. 1991). Since benthic organisms vary in their ability to tolerate hypoxia and in their vulnerability to predators, hypoxia can thus lead to selective predation on some taxa. In Chesapeake Bay, bottomfeeding fishes and crabs increase prey exploitation of some infauna during or after hypoxia as a result of increased prey availability due to their shallower depth distribution (Pihl et al. 1992). Under moderate hypoxia, annelid worms emerge from their burrows and begin undulatory body movements in an attempt to increase the surrounding oxygen levels (Llansò 1991). Following an hypoxic event, the likelihood of predation upon the hypoxic-stressed worm Glycera americana by epibenthic predators (the blue crab Callinectes sapidus and the spot Leiostomus xanthurus) increased with decreasing dissolved oxygen concentration (Nestlerode \& Diaz 1998). Hence, transfer of benthic production to higher trophic levels can either be reduced (e.g. mussels: this study; soft-shelled clams: Taylor \& Eggleston 2000; Baltic clams: Seitz et al. 2003) or increased (e.g. polychaetes: Pihl et al. 1992, Nestlerode \& Diaz 1998) by hypoxia. The experiments described here suggest that in tha Sacca di Goro hypoxia has the potential to alter (perhaps greatly) the importance of trophic pathways by altering predation patterns in individual predator species; interestingly, neither mussel nor crab abundance declined over the long term (C. Munari \& M. Mistri unpubl. data). The results also suggest that shifts in predator-prey interactions probably depend on the behaviour and the susceptibility to hypoxia of the individual interacting species. In the Sacca, the most common potential prey of crabs are Nereis (Neanthes) succinea (up to 140 ind. $\mathrm{m}^{-2}$ ), Oligochaeta (up to 250 ind. $\mathrm{m}^{-2}$ ), Chironomus salinarius (up to 900. ind. $\mathrm{m}^{-2}$ ), Cerastoderma glaucum (up to 20 ind. $\mathrm{m}^{-2}$ ) and Ruditapes philippinarum (up to 400 ind. $\mathrm{m}^{-2}$ in shellfish farming areas) (Mistri et al. 2001a). Being different in their susceptibility to hypoxia, and thus their vulnerabilty to crabs, predator-prey relationships in the Sacca are expected to be altered in a complex manner by hypoxic events.

Acknowledgements. I am grateful to R. Lipcius, R. Seitz, B. Stickle and 1 anonymous reviewer for constructive criticism and helpful suggestions, and to C. Munari and E. Turolla for laboratory assistance. This study is part of the topic 'ALIEN', supported by the Italian Ministry for Agricultural and Forest Policies, VI Triennial Programme for Fishery and Aquaculture.

\section{LITERATURE CITED}

Brante A, Hughes RN (2001) Effect of hypoxia on the preyhanding behaviour of Carcinus maenas feeding on Mytilus edulis. Mar Ecol Prog Ser 209:301-305

Colombo G, Bisceglie R, Zaccaria V, Gaiani V (1994) Variazioni spaziali e temporali delle caratteristiche fisicochimiche delle acque e della biomassa fitoplanctonica della Sacca di Goro. In: Bencivelli S, Castaldi N, Finessi D (eds) Sacca di Goro: studio integrato sull'ecologia. FrancoAngeli, Milano, p 9-82

Crooks JA (1996) The population ecology of an exotic mussel, 
Musculista senhousia, in a southern California bay. Estuaries 19:42-50

Das T, Stickle WB (1994) Detection and avoidance of hypoxic water by juvenile Callinectes sapidus and C. similis. Mar Biol 120:593-600

DeFur PL, Mangum CP, Reese JE (1990) Respiratory responses of the blue crab Callinectes sapidus to longterm hypoxia. Biol Bull (Woods Hole) 178:46-54

Diaz RJ, Rosenberg R (1995) Marine benthic hypoxia: a review of its ecological effects and the behavioural responses of benthic macrofauna. Oceanogr Mar Biol Annu Rev 33:245-303

Eggleston DB, Lipcius RN, Hines AH (1992) Density-dependent predation by blue crabs upon infaunal species with contrasting distribution and abundance patterns. Mar Ecol Prog Ser 85:55-68

Elner RW, Hughes RN (1978) Energy maximization in the diet of the shore crab Carcinus maenas. J Anim Ecol 47: 103-116

Gray JS, Wu RS, Or YY (2002) Effects of hypoxia and organic enrichment on the coastal marine environment. Mar Ecol Prog Ser 238:249-279

Greenway SC, Storey KB (1999) The effect of prolonged anoxia on enzyme activities in oyster (Crassostrea virginica) at different seasons. J Exp Mar Biol Ecol 242: 259-272

Hochachka PW (1997) Oxygen - a key regulatory metabolite in metabolic defense against hypoxia. Am Zool 37: 595-603

Jørgensen BB (1980) Seasonal oxygen depletion in the bottom water of a Danish fjord and its effects on the benthic community. Oikos 34:68-76

Justic D, Legovic T, Rottini-Sandrini L (1987) Trends in oxygen content 1911-1984 and occurrence of benthic mortality in the northern Adriatic Sea. Estuar Coast Shelf Sci 25: $435-445$

Kluytmans JH, DeBont AMT, Kruitwagen ECJ, Ravestein HJL, Veenhof PR (1983) Anaerobic capacities and anaerobic energy production of some Mediterranean bivalves. Comp Biochem Physiol B75:171-179

Lenihan HS, Peterson $\mathrm{CH}$, Byers JE, Grabowski JH, Thayer GW, Colby DR (2001) Cascading of habitat degradation: oyster reefs invaded by refugee fishes escaping stress. Ecol Appl 11:764-782

Llansò RJ (1991) Tolerance of low dissolved oxygen and hydrogen sulfide by the polychaete Streblospio benedicti (Webster). J Exp Mar Biol Ecol 153:165-178

Menge BA, Sutherland JP (1987) Community regulation: variation in disturbance, competition and predation in relation to environmental stress and recruitment. Am Nat 130: 730-757

Mistri M (2002) Ecological characteristics of the invasive Asian date mussel, Musculista senhousia, in the Sacca di Goro (Adriatic Sea, Italy). Estuaries 25:431-440

Mistri M (2003) Foraging behaviour and mutual interference in the Mediterranean shore crab, Carcinus aestuarii, preying upon the immigrant mussel Musculista senhousia. Estuar Coast Shelf Sci 56:155-159

Mistri M (2004) Prey preference of Carcinus aestuarii: possible implications with the control of an invasive mytilid and Manila clam culture in a northern Adriatic lagoon. Aquaculture 230:261-272

Mistri M, Rossi R, Fano EA (2001a) Structure and secondary

Editorial responsibility: Otto Kinne (Editor),

Oldendorf/Luhe, Germany production of a soft bottom macrobenthic community in a brackish lagoon (Sacca di Goro, northeastern Italy). Estuar Coast Shelf Sci 52:605-616

Mistri M, Fano EA, Rossi R (2001b) Redundancy of macrobenthos from lagoonal habitats in the Adriatic Sea. Mar Ecol Prog Ser 215:289-296

Mistri M, Rossi R, Fano EA (2004) The spread of an alien (Musculista senhousia, Bivalvia) in the Sacca di Goro lagoon (Adriatic Sea, Italy). J Molluscan Stud (in press)

Mori M, Manconi R, Fanciulli G (1990) Notes on the reproductive biology of Carcinus aestuarii Nardo (Crustacea, Decapoda) from the lagoon of San Teodoro (Island of Sardinia, Italy). Riv Idrobiol 29:763-774

Nestlerode JA, Diaz RJ (1998) Effects of periodic environmental hypoxia on predation of a tethered polychaete, Glycera americana: implications for trophic dynamics. Mar Ecol Prog Ser 172:185-195

Nilsson HC, Rosenberg R (1994) Hypoxic response of two marine benthic communities. Mar Ecol Prog Ser 115: $209-217$

Pihl L, Baden SP, Diaz RJ (1991) Effects of periodic hypoxia on distribution of demersal fish and crustaceans. Mar Biol 108:349-360

Pihl L, Baden SP, Diaz RJ, Schaffner LC (1992) Hypoxiainduced structural changes in the diet of bottom-feeding fish and Crustacea. Mar Biol 112:349-361

Ritter C, Montagna PA (1999) Seasonal hypoxia and models of benthic response in a Texas Bay. Estuaries 22:7-20

Rosenberg R, Hellman B, Johansson B (1991) Hypoxic tolerance of marine benthic fauna. Mar Ecol Prog Ser 79: $127-131$

Seitz RD, Lipcius RN, Hines AH, DB Eggleston (2001) Density-dependent predation, habitat variation, and the persistence of marine bivalve prey. Ecology 82:2435-2451

Seitz RD, Marshall LS, Hines AH, Clark KL (2003) Effects of hypoxia on predator-prey dynamics of the blue crab Callinectes sapidus and the Baltic clam Macoma balthica in Chesapeake Bay. Mar Ecol Prog Ser 257:179-188

Sokal RR, Rohlf FJ (1981) Biometry: the principles and practice of statistics in biological research, 2nd edn. WH Freeman, New York

Stachowitsch M (1984) Mass mortality in the Gulf of Trieste: the course of community destruction. PSZN I: Mar Ecol 5: $243-264$

Tallqvist M (2001) Burrowing behaviour of the Baltic clam Macoma balthica: effects of sediment type, hypoxia and predator presence. Mar Ecol Prog Ser 212:183-191

Taylor EW, Butler PJ, Al-Wassia A (1977) Some responses of the shore crab, Carcinus maenas (L.), to progressive hypoxia at different acclimation temperatures and salinities. J Comp Physiol 122:391-402

Taylor LT, Eggleston DB (2000) Effect of hypoxia on an estuarine predator-prey interaction: foraging behavior and mutual interference in the blue crab Callinectes sapidus and the infaunal clam prey Mya arenaria. Mar Ecol Prog Ser 196:221-237

Ueda N, Tsutsumi H, Yamada M, Hanamoto K, Montani S (2000) Impacts of oxygen-deficient water on the macrobenthic fauna of Dokai Bay and on adjacent intertidal flats, in Kitakyushu, Japan. Mar Pollut Bull 40:906-913

Underwood AJ (1997) Experiments in ecology: their logical design and interpretation using analysis of variance. Cambridge University Press, Cambridge

Submitted: January 9, 2004; Accepted: April 8, 2004

Proofs received from author(s): June 25, 2004 